\title{
In silico study of active compounds ADMET Profiling in Curcuma xanthorrhiza Roxb and Tamarindus indica as Tuberculosis Treatment
}

\author{
Author \\ Sherry Aristyani ${ }^{1}$, M. Irsyad Nur ${ }^{1}$, Sri Widyarti ${ }^{2}$, Sutiman B. Sumitro ${ }^{2} *$ \\ Affiliation
${ }^{1}$ Graduate student of Biology Department, Faculty of Mathematics and Natural Sciences, University of Brawijaya, Indonesia \\ ${ }^{2}$ Biology Department, Faculty of Mathematics and Natural Sciences, University of Brawijaya, Indonesia
}

\section{Keyword \\ - Curcuma xanthorrhiza Roxb \\ - In silico \\ O Pharmacokinetics \\ - Tamarindus indica $\mathrm{L}$ \\ $\rightarrow$ Tuberculosis}

Received 5 September 2018 Revised 22 Oktober 2018 Accepted 6 November 2018

* Corresponding author Sutiman B. Sumitro University of Brawijaya, Malang 65145, Indonesia Email: sutiman@ub.ac.id

\section{ABSTRACT}

Curcuma xanthorrhiza Roxb and Tamarindus indica L. have been used for a long time by Indonesia local societies as tuberculosis therapy. This study explores the active compounds of Curcuma xanthorrhiza Roxb and Tamarindus indica $L$ that important for suppressing the survival of Mycobacterium tuberculosis and predicts the pharmacokinetics and toxicity of the compounds. stringApp of Cytoscape 3.6.0 was used for screening the compounds targeting mycobacteria proteins, then computational tools like SwissADME (http://swissadme.ch/) and admetSAR (http://Immd.ecust.edu.cn/admetsar1/predict/) were applied for estimating absorption, distribution, metabolism, excretion, and toxicity (ADMET) of active compounds. The result has been shown that there were some active compounds could target proteins of Mycobacterium tuberculosis. According to the profiling result, these compounds had a various characteristic in gastrointestinal absorption, could pass the blood-brain barrier, and had drug-like properties. In toxicity term, the active compounds did not cause Ames toxicity.

\section{INTRODUCTION}

Tuberculosis (TB) is a serious public health problem, one of the leading causes of mortality worldwide, infecting about 9 million people, kills approximately 2 million people annually. The global incidence rate for TB is growing each year by approximately $1.1 \%$ and the number of cases by about $2.4 \%$. The resistance of anti-TB drugs continued to be recognized as a clinical problem in the 21st century. As a result, multidrugresistant and extensively drug-resistant TB are now becoming a major threat to health worldwide, accounting for almost 3\% of all newly reported cases of TB. Due to the increased drug-resistant strains of bacteria such as Mycobacterium tuberculosis and methicillin-resistant Staphylococcus aureus, there has been renewed interest in herbal as potential sources of novel antibiotics. The World Health Organization estimated that 
annual global use of herbal medicines is about the US $\$ 83$ billion in 2008 , indicating that natural products are important sources of new therapeutics and future medicines (WHO, 2015).

The use of herbal as medicine is well known in rural areas of many developing countries. Most herbal medicines are well tolerated by the patient, with fewer unintended consequences than synthetic medicine. Herbs typically have fewer side effects than synthetic medicine and may be safer to use over time (Cragg \& Newman, 2013; Sudjarwo\& Koerniasari; 2017). The findings of the new antibacterial compounds in herbal became one of the remarkable alternatives for treatments since they are rich in numerous varieties of secondary metabolites such as alkaloids, flavonoids, tannins, saponin, and phenolic compounds with antibacterial properties (Jyoti \& Rajeshwari, 2012). Medicinal plant products have long been used as antibacterial in traditional medicines, for the treatment of many diseases such as TB.

The anti-Mycobacterium tuberculosis of medicinal plant products has become subject to scientific investigations currently worldwide, and their active components provide a potential alternative to conventional anti- Mycobacterium tuberculosis. In this context, the development of medicinal plant productbased drug candidates as anti- Mycobacterium tuberculosis has gained momentum in research studies directed toward the design and discovery of drugs. Absorption, distribution, metabolism, and excretion (ADME) is a term of the pharmacokinetic described character of the drugs or compounds while in the human body. The ADME information gives profile drug candidate and is used to design a drug with effectively and safely. Poor ADME and toxicity information of the compound is one of the major reason for terminating drug design development (Tsaioun et al. 2016).

This study tried to explore by computation study to profile ADME of the active compounds of Curcuma xanthorrhiza Roxb and Tamarindus indica $\mathrm{L}$, which have been used for long time by Indonesia local society to treat tuberculosis (Sa'roni 2009; Sa'roni et al. 2011).

\section{METHODS}

\section{Bioactive compounds screening}

55 active compounds of Curcuma xanthorrhiza Roxb and 56 active compounds of Tamarindus indica were used (Jantan et al. 2012; Mary et al. 2012; Ruslay et al. 2007; Sudjaroen et al. Wong, et al. 1998). stringApp of
Cytoscape 3.6.0 (Szklarczyk et al. 2017) was used to screen the active compounds targeting Mycobacterium tuberculosis proteins. 4.0 confidence score cutoff was applied to screen the protein targets. This software resulted in network graphics of compounds-proteins with details: proteins and compounds were indicated as nodes and compounds-proteins were shown as edges.

\section{ADME and toxicity profiling}

PubChem

database (https://pubchem.ncbi.nlm.nih.gov/) was applied to get the SMILE structures used for further analysis. SwissADME (http://swissadme.ch/) and admetSAR (http://Immd.ecust.edu.cn/admetsar1/predict/) were used to obtain pharmacokinetics and toxicity information (Cheng et al. 2012; Daina et al. 2017). The bioactivity prediction was calculated with molinspiration (http://www.molinspiration.com/cgibin/properties).

\section{HASIL DAN PEMBAHASAN}

According to the selection of protein target in Mycobacterium tuberculosis with stringApp of Cytoscape 3.6.0. there were three compounds of Curcuma xanthorrhiza Roxb and five compounds of Tamarindus indica targeting Mycobacterium tuberculosis' protein, (Table 1).

The result showed that bisdemethoxycurcumin had interaction with polyketide synthases (PKSs), a large family protein of producing various natural compounds. In Mycobacterium tuberculosis term PKS proteins like Pks 11 and Pks 18 reported had a role in the long-chain $\alpha$-pyrones synthesis, which is an essential compound in mycobacterium cell wall (Saxena et al. 2003). $\alpha$-pinene could bind the 20 cytochrome P450 enzymes of Mycobacterium tuberculosis, involved in mycobacterial survival and pathogen in a human cell. Recently, it was reported that cyp144 and cyp130 encoded respectively by Rv1777 and Rv1256c could bind azole (Ouellet et al. 2008, Chenge et al. 2016), an antifungal drug that has anti-TB potent and it has been developing to be multidrug-resistant TB therapy(Gupta et al. 2015). Isoamyl alcohol and furfural were showed that had interaction with alcohol dehydrogenase proteins. Lauric acid had interaction with fas, which plays in fatty acid synthase. Salicylate had interaction with various proteins like : caeA which involved in modifying envelope structure of Mycobacterium 
Tabel 1. The compounds targeting Mycobacterium tuberculosis' protein

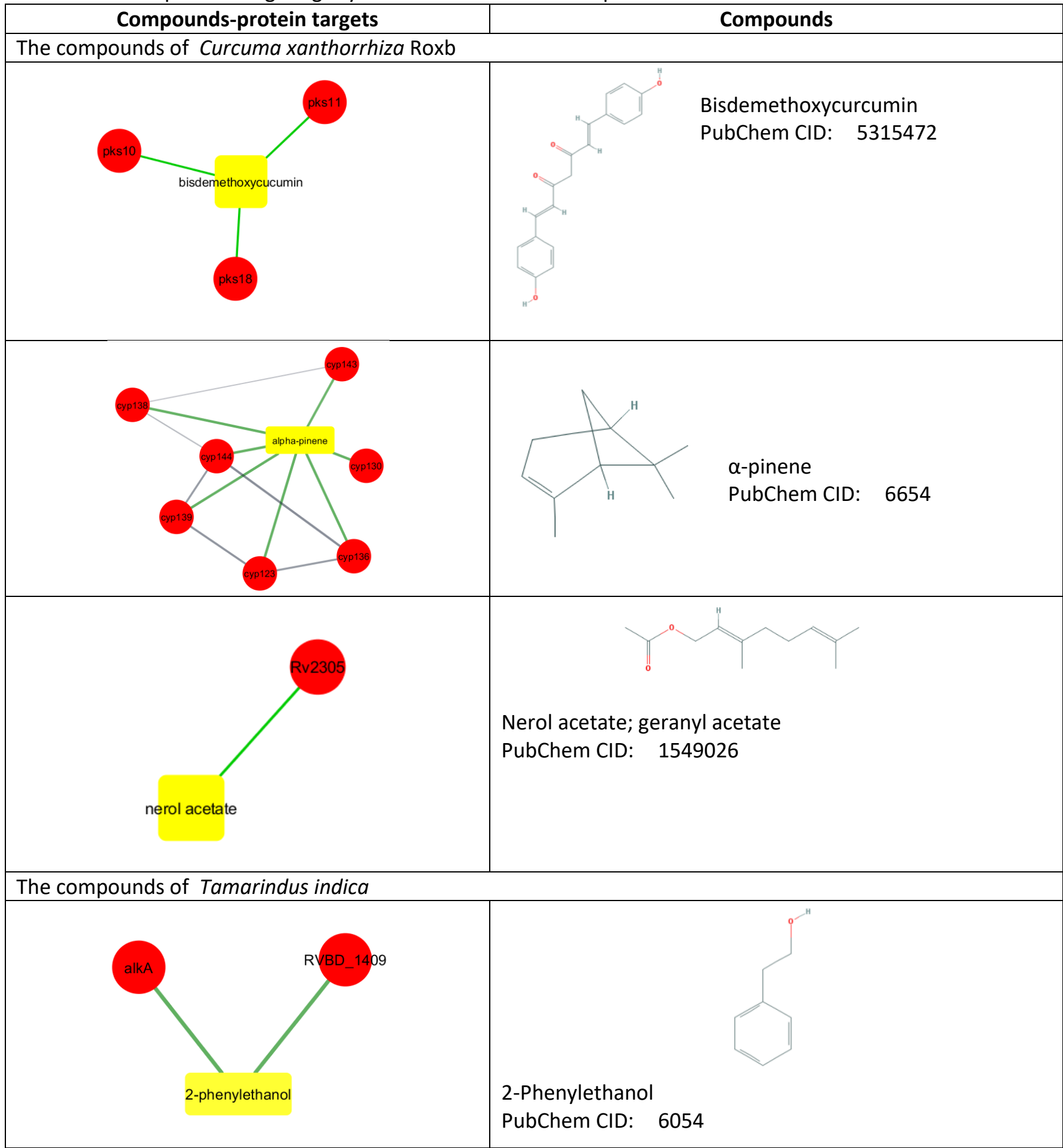


Lanjutan Tabel 1. The compounds targeting Mycobacterium tuberculosis' protein

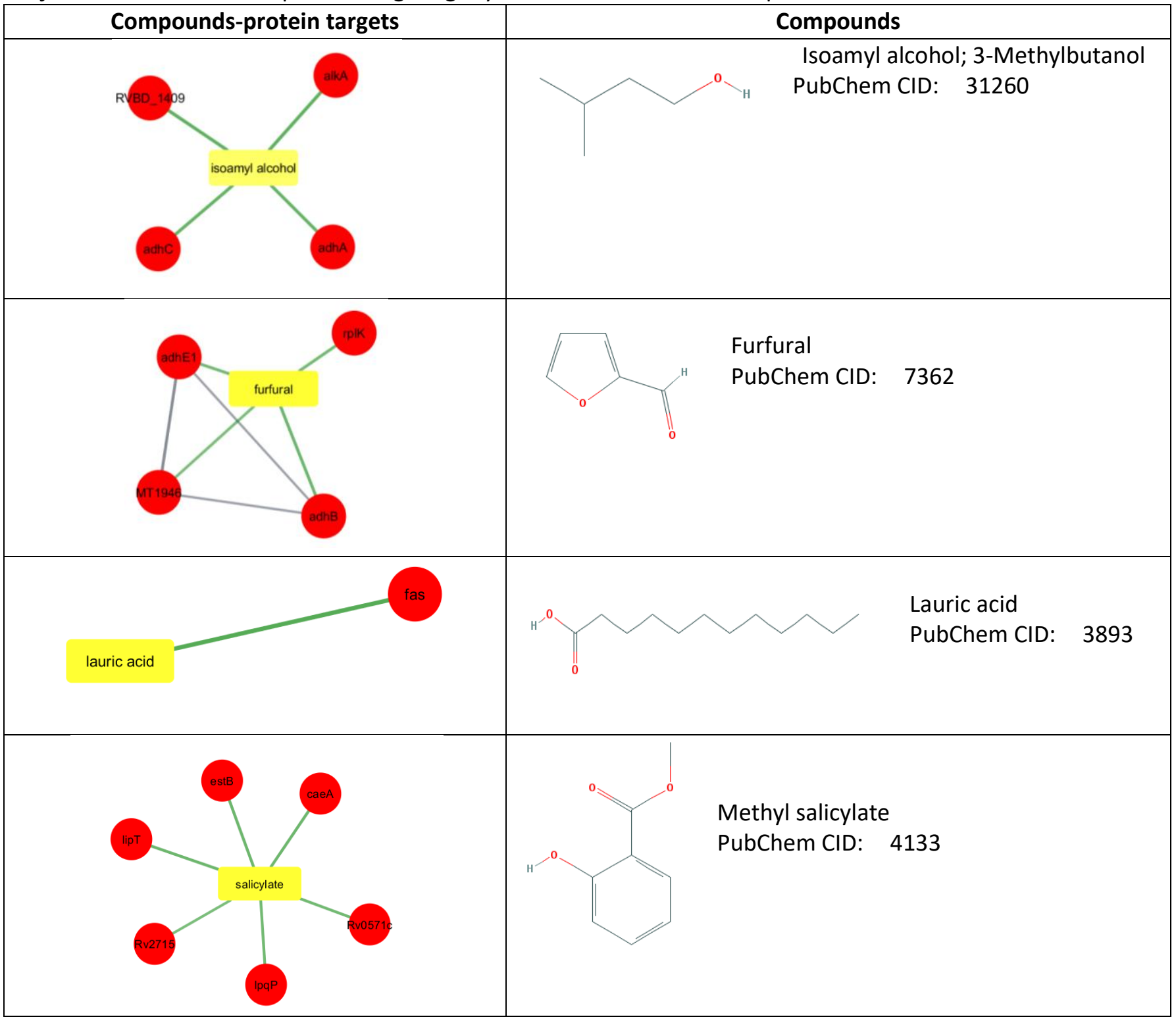

Yellow square: active compound; red circle: proteins of Mycobacterium tuberculosis; green line: compound-protein interaction; gray line: protein-protein interaction

tuberculosis and in protecting mechanism by destructing lipid toxic potential (Lun and Bishai 2007). IpqP is an encoding a membrane-bound lipoprotein, the mutation of IpqP was reported that could alter the morphological colony and cell aggregation, disruption surface motility and biofilm formation and cell division (Nguyen et al. 2010), LipT plays a role as hydrolysing lipids from liposome suspensions, (Fozo and Rucks, 2016), and estB has hydrolase and peroxidase activity. The result of (Table 2) showed the characteristic of the active compounds. According to the (Table 2 ), all of the bioactive compounds had to vary the value of molecular weight from 308 to $96 \mathrm{~g} / \mathrm{mol}$, Increasing molecular weight was associated with poor bioavailability, poor fraction absorbed, higher bound fraction and poor renal clearance (Sakaeda et al. 2001). Polar surface area describes as molecule surface that arises from polar atoms like oxygen, nitrogen or hydrogen attached with oxygen or nitrogen atoms. Molecules had more than $140 \AA^{2}$ were poor absorb into the cell membranes (Clark, 2011; Pajouhesh \& Lenz, 2005). The TPSA value showed that bioactive compounds were less than $140 \AA^{2}$. It indicated that active compounds were easy to enter the cells. The

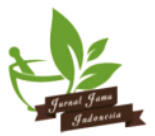


Table 2. Chemical Properties

\begin{tabular}{|c|c|c|c|c|c|c|c|}
\hline Compound & $\begin{array}{c}\mathrm{MW} \\
\text { (g/mol) }\end{array}$ & TPSA $\left(\AA^{2}\right)$ & HBA & HBD & $\begin{array}{c}\text { Rotatable } \\
\text { Bond }\end{array}$ & MLogP & $\begin{array}{c}\text { Water } \\
\text { Solubility }\end{array}$ \\
\hline Bisdemethoxycurcumin & 308.33 & 74.60 & 4 & 2 & 6 & 2.13 & Soluble \\
\hline$\alpha$ - pinene & 136.23 & 0.00 & 0 & 0 & 0 & 4.29 & Soluble \\
\hline Nerol Acetate & 196.29 & 26.30 & 2 & 0 & 6 & 2.95 & Soluble \\
\hline 2-phenyl ethanol & 122.16 & 20.23 & 1 & 1 & 2 & 1.87 & $\begin{array}{l}\text { Very } \\
\text { soluble }\end{array}$ \\
\hline Isoamyl alcohol & 88.15 & 20.23 & 1 & 1 & 2 & 1.16 & $\begin{array}{l}\text { Very } \\
\text { soluble }\end{array}$ \\
\hline Furfural & 96.08 & 30.21 & 2 & 0 & 1 & -0.56 & $\begin{array}{l}\text { Very } \\
\text { soluble }\end{array}$ \\
\hline Lauric acid & 200.32 & 37.30 & 2 & 1 & 10 & 3.51 & Soluble \\
\hline Methyl salicylate & 152.15 & 46.53 & 3 & 1 & 2 & 1.32 & Soluble \\
\hline
\end{tabular}

MW: molecular weight; TPSA: Topology Polar Surface Area, HBA: Hydrogen bond acceptor; HBD: Hydrogen bound donor; MLogP: partition coefficient

value of Log P of compounds varied from -0.56 to 4.29 , the more $\log P$ value the less hydrophilicity of the compounds, and it indicated poor bioavailability (Singh, 2016). The chemical properties of the compounds like molecular weight, TPSA, hydrogen bond acceptor and donor, and $\log P$ value determine the compounds druglikeness. The drug-likeness value was shown in (Table 3). Based on these result all of the compounds were allowed by Lipinski, Veber, and Egan. Meanwhile, $\alpha$ - pinene, 2-phenyl ethanol, furfural, and methyl salicylate were not allowed by Ghose, whereas $\alpha$ pinene, nerol acetate, 2-phenyl ethanol, isoamyl alcohol, furfural and methyl salicylate were not allowed by Muegge.

The bioactive prediction was shown in (Table 4). In this term, score more than 0.0 indicate high activity, 0.0 to -0.5 indicate moderate activity and less than -0.5 indicate inactivity (Paramashivam et al. 2015). According to the result, bisdemethoxycurcumin, $\alpha$ pinene, nerol acetate, and lauric acid had moderate activity as $\mathrm{G}$ protein-coupled receptor ligands. In an ion channel modulator term, nerol acetate indicates high activity followed by bisdemethoxycurcumin, $\alpha$ - pinene, and methyl salicilate that indicate moderate activity. Bisdemethoxycurcumin, a compound that had the moderate capability as a kinase inhibitor, whereas other compounds had inactivity. Bisdemethoxycurcumin has also had the high ability of nuclear receptor ligands, then it was followed by lauric acid and nerol acetate, which had moderate activity score. Bisdemethoxycurcumin and lauric acid were found as protease inhibitor rather than other compounds. Nerol acerate, bisdemethoxycurcumin, and lauric acid had the better ability as enzyme inhibitor than methyl salicylate and $\alpha$ - pinene. From this result, it might be concluded that bisdemethoxycurcumin had good potential in all of these parameters rather than 2-phenyl ethanol, isoamyl alcohol, and furfural that had inactivity score in all parameters.

Based on the pharmacokinetics prediction result (Table 5), all of the compounds had high ability in intestinal absorption (exclude $\alpha$-pinene), blood-brainbarrier penetration, and none prediction as $\mathrm{P}$-gp substrate. It indicated that all of the compounds could spread through all of the body to suppress the deployment of Mycobacterium tuberculosis when entering the human body. In metabolism of xenobiotics term, most of the compounds had no potential to inhibit $\mathrm{P} 450$ proteins. However, bisdemethoxycurcumin could be an inhibitor of CYP1A2, CYP2C9, CYP3A4, and 2-phenyl ethanol as an inhibitor of CYP1A2. According to Flockhart (2007), the inhibition ability of this protein could increase the compounds in the blood plasma and could be decreased in the clearance of substrates. In addition, The toxicity prediction (Table 6) described that all of the compounds could not induce bacteria mutation, thus it might be indicate that all of the compounds did not cause drug resistance. 
Table 3. Druglikenes of the compounds

\begin{tabular}{lcccccc}
\hline \multirow{2}{*}{ Compound } & \multicolumn{3}{c}{ Druglikeness } & Bioavailability \\
\cline { 2 - 5 } & Lipinski & Ghose & Veber & Egan & Muegge & Score \\
\hline Bisdemethoxycurcumin & Yes & Yes & Yes & Yes & Yes & 0.55 \\
a-pinene & Yes & No & Yes & Yes & No & 0.55 \\
Nerol Acetate & Yes & Yes & Yes & Yes & No & 0.55 \\
2-phenyl ethanol & Yes & No & Yes & Yes & No & 0.55 \\
Isoamyl alcohol & Yes & No & Yes & Yes & No & 0.55 \\
Furfural & Yes & No & Yes & Yes & No & 0.55 \\
Lauric acid & Yes & Yes & Yes & Yes & Yes & 0.56 \\
Methyl salicylate & Yes & No & Yes & Yes & No & 0.55 \\
\hline
\end{tabular}

Table 4. Bioactivity prediction

\begin{tabular}{lcccccc}
\hline \multicolumn{1}{c}{ Compound } & GPCR & ICM & KI & NRL & PI & EI \\
\hline Bisdemethoxycurcumin & 0.00 & -0.14 & -0.26 & 0.25 & -0.08 & 0.15 \\
$\alpha$ - pinene & -0.48 & -0.43 & -1.50 & -0.62 & -0.85 & -0.34 \\
Nerol Acetate & -0.50 & 0.04 & -1.11 & -0.12 & -0.80 & 0.21 \\
2-phenyl ethanol & -2.00 & -1.28 & -2.11 & -2.08 & -2.08 & -1.38 \\
Isoamyl alcohol & -3.58 & -3.53 & -3.69 & -3.55 & -3.38 & -3.52 \\
Furfural & -3.76 & -3.78 & -3.86 & -3.81 & -3.92 & -3.80 \\
Lauric acid & -0.27 & -0.04 & -0.75 & -0.24 & -0.36 & 0.04 \\
Methyl salicylate & -1.14 & -0.55 & -1.22 & -1.03 & -1.27 & -0.62 \\
\hline
\end{tabular}

GPCR: G protein-coupled receptor ligands; ICM: ion channel modulators; KI: kinase inhibitor; NRL: nuclear receptor ligands; PI: protease inhibitor; EI: enzyme inhibitor

Table 5. Pharmacokinetics prediction

\begin{tabular}{lcccccccc}
\hline Compound & GI & BBB & P-gp & $\begin{array}{l}\text { CYP1A2 } \\
\text { inhibitor }\end{array}$ & $\begin{array}{l}\text { CYP2C19 } \\
\text { inhibitor }\end{array}$ & $\begin{array}{l}\text { CYP2C9 } \\
\text { inhibitor }\end{array}$ & $\begin{array}{l}\text { CYP2D6 } \\
\text { inhibitor }\end{array}$ & $\begin{array}{l}\text { CYP3A4 } \\
\text { inhibitor }\end{array}$ \\
\hline Bisdemethoxycurcumin & High & Yes & No & Yes & No & Yes & No & Yes \\
$\alpha$-pinene & Low & Yes & No & No & No & Yes & No & No \\
Nerol Acetate & High & Yes & No & No & No & No & No & No \\
2-phenyl ethanol & High & Yes & No & Yes & No & No & No & No \\
Isoamyl alcohol & High & Yes & No & No & No & No & No & No \\
Furfural & High & Yes & No & No & No & No & No & No \\
Lauric acid & High & Yes & No & No & No & No & No & No \\
Methyl salicylate & High & Yes & No & No & No & No & No & No \\
\hline
\end{tabular}

GI absorption: gastrointestinal absorption; BBB permeant: Blood-Brain-Barrier permeant; P-gp: permeability glycoprotein substrate

\section{CONCLUSION}

The compounds of Curcuma xanthorrhiza Roxb such as bisdemethoxycurcumin, $\alpha$ - pinene, and nerol acetate, and 2-phenyl ethanol, isoamyl alcohol, furfural, lauric acid, and methyl salicylate of Tamarindus indica targeted proteins of Mycobacterium tuberculosis that had potential as anti-tuberculosis. According to theADME profiling, all of these compounds had various chemical characteristics and bioactivity. However, all of the compounds were allowed by Lipinski, Veber, Egan's rule, and it could be easier to absorb in the blood-brain-barrier system. In toxicity term, all of the compounds had non-ames toxicity, thus it will not cause resistance in order to avoid multi-drug resistance TB. In this study did not mention the possible interaction with other molecules and also the interaction of active compounds with human proteins related with the immune system and

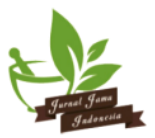


energy distribution mechanism to suppress the dissemination of Mycobacterium tuberculosis in the human body, therefore further investigations and laboratory works are needed to overcome TB problems.

\section{REFERENCES}

Cheng F, Li W, Zhou Y, Shen J, Wu Z, Liu G, Lee PW, Tang Y. 2012. AdmetSAR: A comprehensive source and free tool for assessment of chemical ADMET properties. Journal of Chemical Information and Modeling. 52 (11): 3099-3105

Chenge J, Kavanagh ME, Driscoll MD, McLean KJ, Young DB, Cortes T, Matak-Vinkovic D, Levy CW, Rigby SEJ, Leys $D$ et al. 2016. Structural characterization of CYP144A1-a cytochrome P450 enzyme expressed from alternative transcripts in Mycobacterium tuberculosis. Scientific Reports. 6:1-12.

Clark DE. 2011. What has polar surface area ever done for drug discovery. Future Medicinal Chemistry. 3(4): 469-484.

Cragg GM, Newman DJ. 2013. Natural products:A continuing source of novel drug. Biochimica et Biophysica Acta. 1830 (6):3670-3695.

Daina A, Michielin O, Zoete V. 2017. SwissADME: A free web tool to evaluate pharmacokinetics, druglikeness and medicinal chemistry friendliness of small molecules. Scientific Reports. 7: 1-13.

Flockhart DA. 2007. Drug Interactions: Cytochrome P450 Drug Interaction Table. Indiana University School of Medicine "/clinpharm/ddis/clinical-table/" Accessed Agustus 12th 2018

Fozo EM, Ruck EA. 2016. The Making and Taking of Lipids: The Role of Bacterial Lipid Synthesis and the Harnessing of Host Lipids in Bacterial Pathogenesis. In. Pole RK. Advances in Microbial Physiology. London: Academic Press

Gupta UD, Vemuri N, Gupta P, Kumar V, Tanushree P, Khuller GK. 2015. Efficacy of moxifloxacin \& econazole against multidrug resistant (MDR) Mycobacterium tuberculosis in murine model. Indian Journal of Medical Research. 142(3):323-329.

Jantan I, Saputri FC, Qaisar MN, Buang F. 2012. Correlation between chemical composition of Curcuma domestica and Curcuma xanthorrhiza and their antioxidant effect on human low-density lipoprotein oxidation. Evidence-Based Complementary and Alternative Medicine. 2012
Jyoti S, Rajeshwari S. 2012. Evaluation of phytochemical constituents in conventional and non-conventional species of curcuma. International Research Journal of Pharmacy. 3(8):203-204.

Lun S, Bishai WR. 2007. Characterization of a novel cell wall-anchored protein with carboxylesterase activity required for virulence in Mycobacterium tuberculosis. Journal of Biological Chemistry. 282(25):18348-18356.

Mary HPA, Susheela GK, Jayasree S, Nizzy AM, Rajagopal B, Jeeva S. 2012. Phytochemical characterization and antimicrobial activity of Curcuma xanthorrhiza Roxb. Asian Pacific Journal of Tropical Biomedicine. 2(2): S637-S640.

Nguyen HT, Wolff KA, Cartabuke RH, Ogwang S, Nguyen L. 2010. A lipoprotein modulates activity of the MtrAB two-component system to provide intrinsic multidrug resistance, cytokinetic control and cell wall homeostasis in Mycobacterium. Molecular Microbiology. 76(2):348-364.

Ouellet H, Podust LM, De Montellano PRO. 2008. Mycobacterium tuberculosis CYP130: Crystal structure, biophysical characterization, and interaction with antifungal azole drugs. Journal of Biological Chemistry. 283(8):5069-5080.

Pajouhesh H, Lenz GR. 2005. Medicinal Chemical Properties of Successful Central Nervous System Drugs. NeuroRx. 2(4): 541-553.

Paramashiwam SK, Elayaperumal K, Natarajan BB, Ramamoorthy MD, Balasubramanian S, Dhiraviam KN. 2015. In silico pharmacokinetic and molecular docking studies of small molecules derived from Indigofera aspalathoides Vahl targeting receptor tyrosine kinases. Bioinformation.11(2):73-84

Ruslay S, Abas F, Shaari K, Zainal Z, Maulidiani, Sirat H, Israf A, Lajis NH. 2007. Characterization of the components present in the active fractions of health gingers (Curcuma xanthorrhiza and Zingiber zerumbet) by HPLC-DAD-ESIMS. Food Chemistry. 104(3): 1183-1191

Sakaeda T., Okamura N, Nagata S, Yagami T, Horinouchi M, Okumura K, Yamashita F, Hashida M. 2001. Molecular and pharmacokinetic properties of 222 commercially available oral drugs in humans. Biological \& Pharmaceutical Bulletin. 24(8): 935-40.

Saxena P, Yadav G, Mohanty D, Gokhale RS. 2003. A New Family of Type III Polyketide Synthases in Mycobacterium tuberculosis. Journal of Biological Chemistry. 278:44780-44790. 
Singh D. 2016. Defining desirable natural product derived anticancer drug space: optimization of molecular physicochemical properties and ADMET attributes. ADMET and DMPK. 4(2): 98-113.

Sudjaroen Y, Haubner R, Würtele G, Hull WE, Erben G, Spiegelhalder B, Changbumrung $\mathrm{S}$, Bartsch $\mathrm{H}$, Owen RW. 2005. Isolation and structure elucidation of phenolic antioxidants from Tamarind (Tamarindus indica L.) seeds and pericarp. Food and Chemical Toxicology. 43(11): 1673-1682.

Sudjarwo SA, Koerniasari GW. 2017. Protective effect of curcumin on lead acetate-induced testicular toxicity in Wistar rats. Research in Pharmaceutical Sciences. 12(5):381-390.
Szklarczyk D, Morris JH, Cook H, Kuhn M, Wyder S, Simonovic M, Santos A, Doncheva N T, Roth A, Bork $P$ et al. 2017. The STRING database in 2017: Qualitycontrolled protein-protein association networks, made broadly accessible. Nucleic Acids Research 45:D362-D368.

WHO. Global Tuberculosis Report. Geneva, Switzerland: WHO; 2015. pp. 1-145.

Wong KC, Tan CP, Chow CH, Chee SG. 1998. Volatile constituents of the fruit of Tamarindus indica $\mathrm{L}$. Journal of Essential Oil Research. 10(2): 219-221. 